\section{MATEMÁTICA E ARTE: UMA AVENTURA COM OS SÓLIDOS GEOMÉTRICOS}

\author{
MATHEMATICS AND ARTS: AN \\ ADVENTURE WITH GEOMETRIC \\ SOLIDS
}

\section{Deniele Pereira Batista ${ }^{17}$}

Resumo: O presente texto apresenta uma proposta pedagógica desenvolvida com alunos do $4^{\circ}$ ano do ensino fundamental nas aulas de matemática. Foram adotadas algumas estratégias na perspectiva da aprendizagem significativa, com a intenção de transcender o ensino tradicional da matemática na escola, aproximando os saberes matemáticos, em especial os do campo da geometria, à vida cotidiana dos alunos. Dentre as estratégias, a arte representou um caminho profícuo para o "fazer matemática" com e pelos alunos, uma vez que os objetos do mundo físico foram explorados por meio de atividades artísticas. Ao término da proposta, foi possível constatar ganhos na aprendizagem dos alunos, na medida em que se apropriaram do tema estudado para desenvolver habilidades matemáticas preconizadas nos documentos de referência sobre o ensino da matemática.

Palavras-chave: Matemática. Arte. Parâmetros Curriculares Nacionais.

\footnotetext{
17 Doutoranda em Educação pela Universidade Católica de Petrópolis. Mestre em Educação pela mesma instituição. Graduada em Pedagogia pela Universidade do Estado do Rio de Janeiro (UERJ). Atuou como professora em Cursos de Licenciatura de instituições privadas, ministrando disciplinas pedagógicas. Atualmente é professora dos anos iniciais do ensino fundamental, lecionando a disciplina Matemática para turmas do $4^{\circ}$ ano, do Colégio de Aplicação da Universidade Federal de Juiz de Fora. Filiação institucional: Colégio de Aplicação da Universidade Federal de Juiz de Fora. Endereço: Rua Visconde de Mauá, 300, Santa Helena, CEP 36015-260, Juiz de Fora/MG. Telefone: (32) 3229-7602. E-mail: deniele.batista@ufjf.edu.br.
}

Abstract: This paper presents an educational proposal developed with 4th graders in elementary school math classes. Some strategies were adopted from the perspective of meaningful learning, with the intention of transcending traditional mathematics teaching at school by bringing mathematical knowledge, especially in the field of geometry, closer to students' daily life. Among such strategies, the arts represented a fruitful way to "do mathematics" with and by the students, since the objects of the physical world were explored through artistic activities. At the end of the proposal, improvements could be observed in students' learning, to the extent that they have made use of the subject studied in order to develop the mathematical skills advocated in the reference documents on mathematics teaching.

Keywords: Mathematics. Arts. National Syllabus Guidelines.

\section{Introdução}

Ao longo dos anos, foram várias as tendências que buscaram a renovação da matemática escolar, sobretudo pelo viés da valorização de situações significativas e contextualizadas. Apesar disso, ainda insiste-se na mera formalização de conceitos e na pouca (ou nenhuma) vinculação com a vida prática ou com a capacidade criativa do aluno, fato que contribui para caracterizar esse campo do saber como uma disciplina historicamente associada mais aos fracassos que produz do que aos sucessos. Talvez possamos atribuir esse quadro ao tradicionalismo pedagógico que ainda assola o ensino da matemática.

Com efeito, o trabalho mecânico, de treinos e repetições, sem sentido para os alunos, rouba-lhes a chance de desenvolver o raciocínio, o pensamento crítico e a autonomia. É importante considerar que os símbolos e os códigos que compõem a linguagem matemática estejam dotados de significação para o aluno, pois, do 
contrário, a aprendizagem fica comprometida.

De um modo geral, podemos dizer que é tarefa (e desafio) do professor, do gestor e do coordenador, fazer com que a construção do conhecimento na escola seja dotada de sentido para o aluno. Com o ensino da matemática não é diferente: D'Ambrosio (2004) alerta que a matemática, como disciplina autônoma dos sistemas escolares, tem se mostrado, em grande parte, obsoleta, inútil e desinteressante. Para o autor, esta disciplina poderia se tornar útil e apreciada na escola se fosse integrada ao mundo moderno, discutindo e analisando os problemas maiores da humanidade, sem perder o lúdico.

Os Parâmetros Curriculares Nacionais de Matemática (1997) destacam o descompasso existente entre os saberes matemáticos necessários ao aluno, tão presentes em sua vida cotidiana - saberes como reconhecer problemas, buscar e selecionar informações e tomar decisões e a forma "distante" (e sem sucesso) pela qual a escola, muitas vezes, apresenta essa disciplina aos alunos. Os PCN defendem uma atividade matemática dotada de significado para o aluno, dada num processo de aprendizagem que o leve a fazer conexões entre a matemática e outras disciplinas e entre ela e o seu cotidiano, como podemos ver no trecho abaixo:

Ao relacionar ideias matemáticas entre si, os alunos podem reconhecer princípios gerais, como proporcionalidade, igualdade, composição e inclusão e perceber que processos como o estabelecimento de analogias, indução e dedução estão presentes tanto no trabalho com números e operações como em espaço, forma e medidas. (BRASIL, 1997, p. 29)

Neste contexto, a adoção de estratégias metodológicas que transcendam o ensino tradicional da matemática escolar pode contribuir para a melhoria desse quadro. Dentre as possíveis estratégias, a arte representou um caminho viável para o "fazer matemática" com e pelos alunos do $4^{\mathrm{o}}$ ano do ensino fundamental de uma escola pública da cidade de Juiz de Fora, em Minas Gerais.

Portanto, é no campo do prazer, da ludicidade e, consequentemente, da aprendizagem significativa, que esta proposta pedagógica se situa. O nosso referencial sobre aprendizagem significativa repousa em David Ausubel, psicólogo educacional da linha cognitivista, que destaca o processo de aprendizagem significativa como o mais importante na aprendizagem. Para Ausubel, "aprendizagem significativa é um processo no qual uma nova informação é relacionada a um aspecto relevante, já existente, da estrutura de conhecimento de um indivíduo" (NOVAK, 1981, p. 56). Ou seja, esse processo envolve a interação da nova informação com uma estrutura cognitiva preexistente, a qual Ausubel chama de subsunçores. Uma aprendizagem significativa, portanto, resulta em crescimento e modificação de um subsunçor já existente.

As atividades didático-pedagógicas que relatarei são parte de um projeto realizado pelas professoras do $4^{\circ}$ ano do ensino fundamental, o Projeto Coletivo de Trabalho (PCT), cujo tema foi "O Estatuto da Criança e do Adolescente: educando para a cidadania". O Estatuto da Criança e do Adolescente (ECA) é uma Lei que dispõe sobre a proteção integral à criança $\mathrm{e}$ ao adolescente. Sobre os direitos fundamentais, destaca:

A criança e o adolescente gozam de todos os direitos fundamentais inerentes à pessoa humana, sem prejuízo da proteção integral de que trata esta lei, assegurando-se-lhes, por lei ou por outros meios, todas as oportunidades e facilidades, a fim de lhes facultar o desenvolvimento físico, mental, moral, espiritual e social, em condições de liberdade e de dignidade. (BRASIL, 2001, artigo $3^{\circ}$, p. 9)

É importante que a criança e o adolescente compreendam que para cada direito que lhes é assegurado, existe uma correlação aos seus deveres. Ou seja, o direito à educação pressupõe o dever de estudar; o direito à saúde, o dever de cuidar 
dela, e assim por diante. Sendo assim, este PCT foi desenvolvido com o objetivo de levar os alunos a: identificar o Estatuto da Criança e do Adolescente (ECA) como uma Lei que estabelece direitos e deveres às crianças e adolescentes, indiscriminadamente; refletir sobre o significado de ser considerado "sujeito de direitos"; reconhecer os direitos fundamentais previstos no ECA, bem como os deveres correspondentes, valorizando a sua importância para a construção da cidadania.

$\mathrm{O}$ tema "Geometria", mais especificamente os sólidos geométricos, representou o elo entre a matemática e o referido PCT, uma vez que permitiu explorar e desenvolver objetivos curriculares do $4^{\circ}$ ano do ensino fundamental, de forma integrada.

\section{A Geometria e a Arte}

De acordo com os Parâmetros Curriculares Nacionais (1997), a geometria constitui parte importante do currículo de matemática no ensino fundamental. Por meio dela, o aluno desenvolve um tipo de pensamento peculiar que lhe favorece a compreensão, a descrição e a representação, de forma organizada, do mundo em que vive (BRASIL, 1997). E mais:

Uma das possibilidades mais fascinantes do ensino de geometria consiste em levar o aluno a perceber e valorizar sua presença em elementos da natureza e em criações do homem. Isso pode ocorrer por meio de atividades em que ele possa explorar formas como as de flores, elementos marinhos, casa de abelha, teia de aranha, ou formas em obras de arte, esculturas, pinturas, arquitetura, ou ainda em desenhos feitos em tecidos, vasos, papéis decorativos, mosaicos, pisos etc. (BRASIL, 1997, p. 83)

Nesta perspectiva, o trabalho pedagógico pautado na exploração e/ou reprodução de objetos do mundo físico, representado, por exemplo, pelas atividades artísticas, ganha destaque. Atividades que envolvem o manuseio e a experimentação pelo aluno tornam-se essenciais para o trabalho com a geometria porque $\mathrm{o}$ contato com as formas geométricas proporciona ao aluno o reconhecimento das propriedades das formas e a elaboração de conceitos geométricos. Com efeito, a contribuição da arte neste trabalho perpassa pelas possibilidades dos alunos de visualizar, perceber e explorar os conteúdos geométricos, de modo a atribuir-lhes significado.

Frequentemente incorporo atividades artísticas em minhas aulas de matemática por acreditar no seu potencial, tanto na perspectiva do ensino quanto da aprendizagem. Quando o aluno aprende com sentido e prazer, compreende mais claramente aquilo que lhe é ensinado.

Minha intenção em atrelar matemática à arte pode ser traduzida por trecho dos Parâmetros Curriculares Nacionais de Arte (1997), quando diz que o ensino de arte deve "garantir ao aluno a liberdade de imaginar e edificar propostas artísticas pessoais ou grupais com base em intenções próprias. E tudo isso integrado aos aspectos lúdicos e prazerosos que se apresentam durante a atividade artística" (p. 35).

\section{As etapas do trabalho}

Para desenvolver os objetivos relativos aos sólidos geométricos, e de forma atrelada ao Projeto Coletivo de Trabalho, foram propostas algumas atividades nas aulas de matemática, as quais descrevo a seguir:

- Leitura do livro "As três partes"

Este livro conta a história de uma casa que resolve se transformar. Para isso, ela se divide em três partes (dois triângulos e um trapézio) que se movem e formam novos objetos de acordo com as aventuras, a imaginação e as experiências. Iniciei o trabalho com a leitura deste livro para despertar nos alunos o senso de relações espaciais e desenvolver conceitos e linguagem da geometria. 
$\mathrm{Na}$ medida em que as aventuras e as experiências são narradas, as três partes se movimentam, formando novos objetos. O texto e as ilustrações deste livro permitem ao professor explorar, de forma prazerosa, junto aos alunos, alguns conteúdos matemáticos, dentre eles, as formas geométricas. O trabalho iniciou com a leitura desse livro para despertar nos alunos a ludicidade que as formas geométricas podem nos proporcionar, além de levá-los a perceber que as formas geométricas estão presentes em nosso cotidiano, tanto nos elementos naturais como nos objetos criados pelo homem. A partir da observação atenta dessas formas, adentramos pelos conceitos sobre os sólidos geométricos.

- Construção de formas geométricas espaciais

\section{Num segundo momento, prosseguimos com o estudo das planificações de sólidos geométricos: poliedros (sólidos de faces planas) e não poliedros (sólidos que apresentam pelo menos uma face arredondada). Os alunos montaram seis sólidos a partir de suas planificações: cubo, paralelepípedo, prisma, pirâmide, cilindro e cone. Alguns deles podem ser vistos nas figuras 2,3 e 4 .}

Figuras 1, 2 e 3: Alguns sólidos planificados

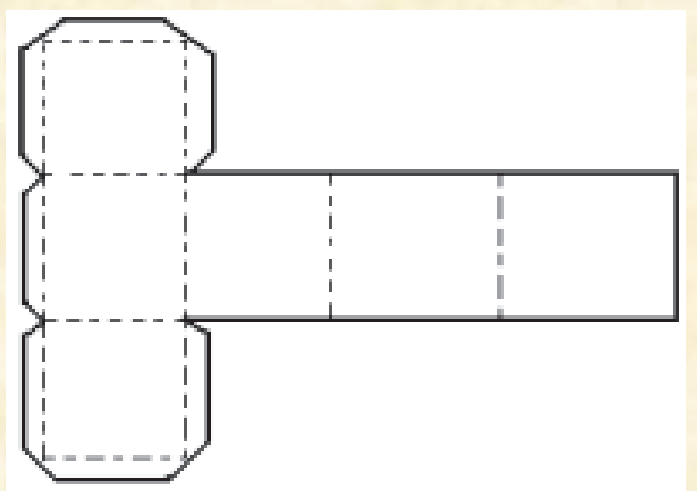

Cubo

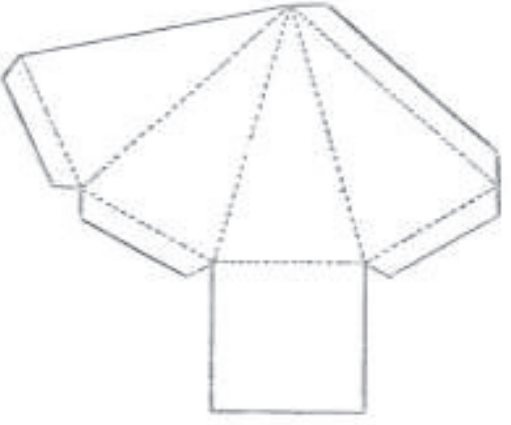

Pirâmide

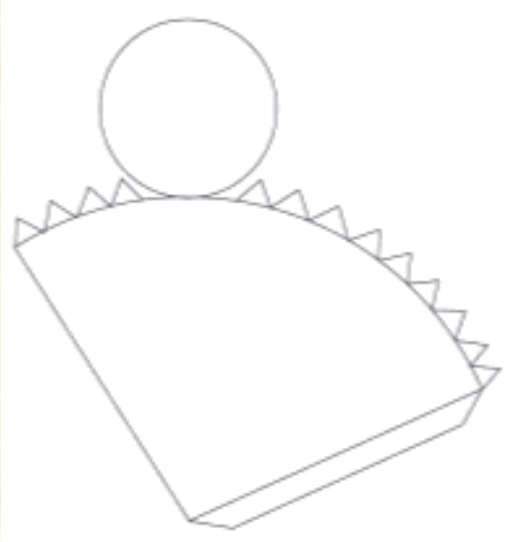

Cone

Nesta etapa, os alunos puderam perceber semelhanças e diferenças entre os sólidos; uns rolam, outros não; uns têm faces planas, outros não; uns possuem cantos, outros não, e assim por diante. Nesse movimento de observação, puderam reconhecer características básicas dos sólidos, bem como fazer inferências relacionadas a semelhanças e diferenças entre eles. Recortando, dobrando e colando, os alunos fizeram a montagem de alguns sólidos, como podemos ver nas figuras 4 e 5 .

Figuras ${ }^{18} 4$ e 5: Exemplos de sólidos montados

${ }^{18}$ Deste ponto em diante, as figuras que aparecem neste trabalho fazem parte do acervo pessoal da autora deste relato de experiência. 


\section{DIVERS@!}
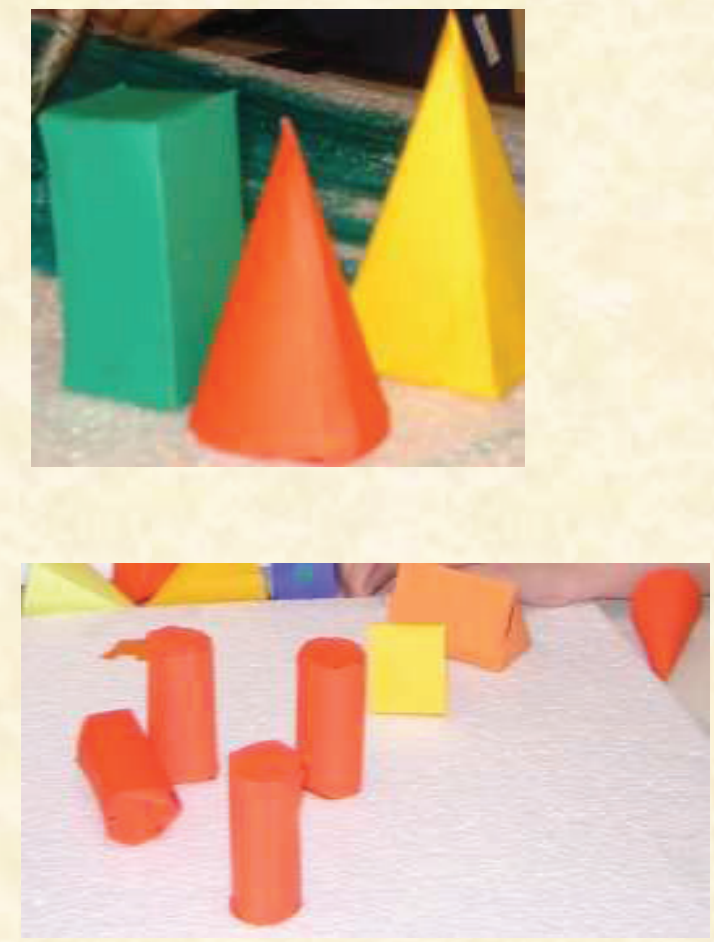

- Construção de maquetes

O manuseio de materiais concretos proporciona o envolvimento do aluno em uma situação de aprendizagem. Por proporcionarem esse tipo de experiência, as maquetes foram privilegiadas neste trabalho.

Sustentada pelo Artigo 71 do Estatuto da Criança e do Adolescente, que prevê que "a criança e o adolescente têm direito à informação, cultura, lazer, esportes, diversões, espetáculos e produtos e serviços que respeitem sua condição peculiar de pessoa em desenvolvimento" (BRASIL, 2001, p. 25), propus aos alunos que utilizassem os sólidos confeccionados para criar maquetes representativas de cenários infantis (parque, praça, castelo, casa de boneca, campo de futebol, entre outros). A ideia central era que esses cenários remetessem à brincadeira e ao lazer, enfim, à ludicidade tão necessária ao desenvolvimento infantil, conforme preconiza o ECA.

São diversos os materiais que podem ser usados na confecção de uma maquete. Os alunos levaram folhas de isopor, papeis coloridos, pedaços de tecido, palitos, argila, embalagens vazias de produtos, como creme dental, remédio, leite, e tantos outros objetos para a confecção das maquetes. Tintas, pinceis, cola, EVA e outros materiais foram fornecidos pela escola.

As figuras 7 e 8 mostram o momento em que os grupos começaram a esboçar suas maquetes.

Figuras 6 e 7: Processo de criação das maquetes


Esta proposta artística despertou o interesse da turma. Na medida em que os grupos avançavam na construção das maquetes, a professora os estimulava a pensar nas formas presentes naquele(s) cenário(s). Com isso, os alunos faziam descobertas e demonstravam surpresa em perceber o quanto o mundo a nossa volta é repleto de sólidos geométricos. Neste ponto, em particular, a matemática e a vida cotidiana dos alunos se aproximaram.

Este trabalho envolveu, portanto, a "observação de formas geométricas presentes em elementos naturais e nos objetos criados pelo homem e de suas características: arredondadas ou não, simétricas ou não etc." (BRASIL, 1997, p. 51). 


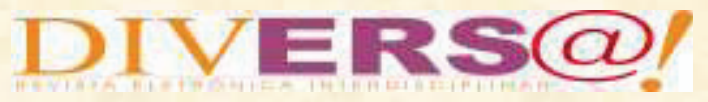

Pracinhas, parque de diversões, pista de skate, campo de futebol e casa de bonecas, são algumas demonstrações daquilo que foi criado pelos grupos, como podemos ver nas figuras a seguir.

Figuras 8, 9 e 10: Exemplos de maquetes criadas pelos alunos
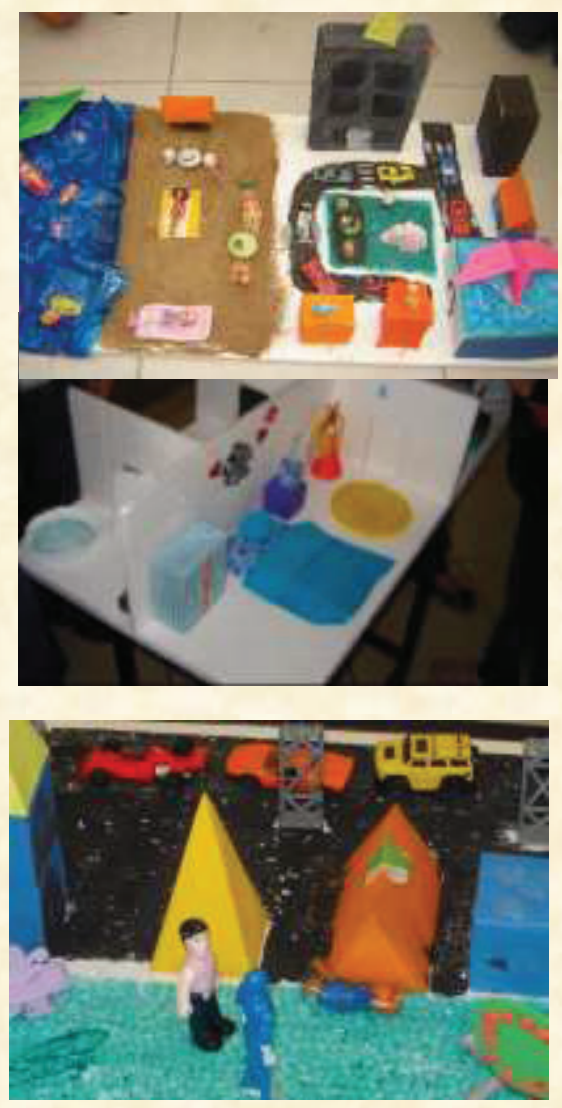

Produção textual

A partir da experiência vivenciada, cada grupo foi levado a registrar a memória do processo de criação, a fim de resgatar o que a maquete representava $\mathrm{e}$ como a viam enquanto possibilidade de proporcionar o direito da criança de brincar, previsto no Estatuto da Criança e do Adolescente. Inicialmente, o registro foi feito de forma manual. Posteriormente, foi digitado pelos alunos em editor de texto, no laboratório de informática da escola.

Figuras 11 e 12: Exemplos de registros da memória do trabalho
A gente fez este trabaho com um campo de futebol, parquinho e uma cidade para a criança se divertirem com os carrinhos, a pracinha etc.

Tudo que as crianças gostam está nesta maquete. Esse trabalho fez a gente se divertir com as coisas interessantes e com as formas geométricas.

Felipe, ARTHUR, MARCELO, Luciano, Jhonata e Raul

Nob pensamos en fazet uma casa de boneca com ditea de lazet, cozinha, sala, basheito equatto como se fosse nossa. fizemos ela com muito catinho pata as stianças beincatem * se divertitem. 6 E dis que toda ctianga tem diteito ao lazat a fizemos a cabinha com piseina que i uma forma das etianceses so divettitam.

Atne fuise, Masia thata. _..... Ninea

\section{- Exposição}

Como culminância do projeto, houve uma exposição das maquetes, momento em que os alunos explicavam oralmente o trabalho realizado. Era visível a satisfação deles em apresentar para os demais alunos da escola suas produções. Afinal, expressar-se por meio de sua própria produção é uma atividade carregada de sentido para quem o faz. Nesta experiência, ao invés de serem meros reprodutores de ideias, os alunos assumiram o papel de autores e coautores de seus projetos.

Abaixo, algumas imagens desta etapa.

Figuras 13, 14 e 15: Exposição dos trabalhos

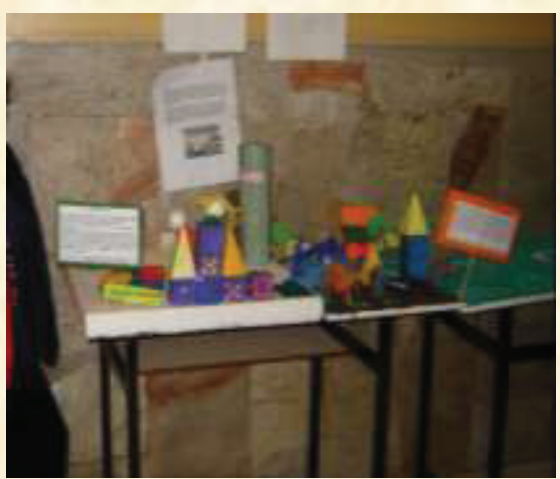




\section{DIVERS@!}
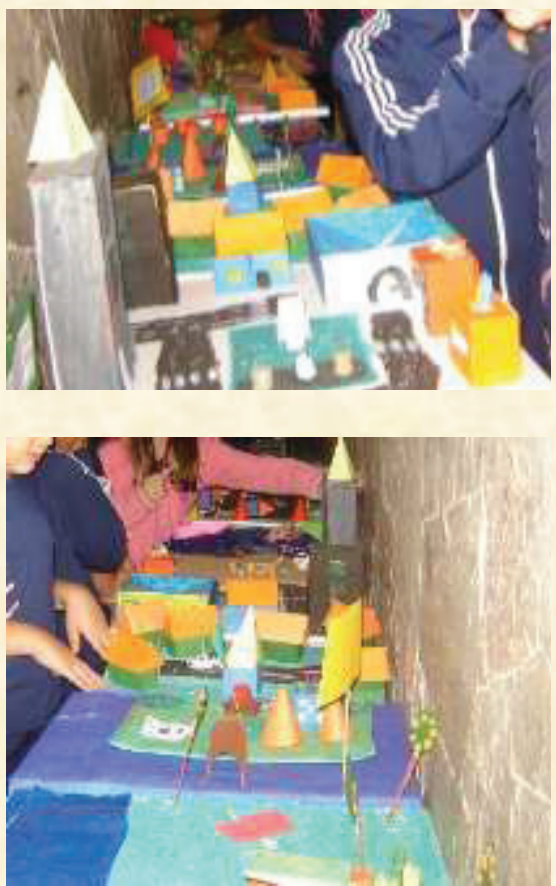

\section{Concluindo}

Ao término da proposta, foi possível constatar ganhos na aprendizagem dos alunos, na medida em que se apropriaram do tema estudado para: a) fazer comparações entre objetos do espaço físico e objetos geométricos (esféricos, cilíndricos, cônicos, cúbicos, piramidais, prismáticos); b) perceber semelhanças e diferenças entre os sólidos geométricos explorados; c) interpretar e representar posições e movimentos no espaço; d) representar o espaço por meio de maquetes. Importa observar que tais habilidades estão em consonância com aquilo que é preconizado nos Parâmetros Curriculares Nacionais de Matemática.

Desenvolver um trabalho pedagógico na perspectiva da aprendizagem significativa pressupõe a concepção de uma matemática atrelada à realidade, presente àquilo que nos cerca $\mathrm{e}$, por isso mesmo, entendê-la e vivenciá-la de forma prática, construindo-a e reconstruindo-a. $\mathrm{O}$ trabalho desenvolvido com esta turma de $4^{\mathrm{O}}$ ano do ensino fundamental foi fruto desta maneira de pensar matemática. Como a geometria foi trabalhada num contexto que confere sentido para o aluno, minha compreensão é a de que aprendizagens significativas foram
proporcionadas.

\section{Referências}

BRASIL. Estatuto da criança e do adolescente (1990). Estatuto da criança e do adolescente: Lei n. 8.069, de 13 de julho de 1990, Lei n. 8.242, de 12 de outubro de 1991. - 3. ed. - Brasília : Câmara dos Deputados, Coordenação de Publicações, 2001.

$\begin{array}{lrr} & \text { Secretaria de } & \text { Educação } \\ \text { Fundamental. } & \text { Parâmetros } & \text { curriculares } \\ \text { nacionais: } & \text { matemática. } & \text { Brasília: }\end{array}$
MEC/SEF, 1997.

Secretaria de Educação Fundamental. Parâmetros curriculares nacionais: arte. Brasília: MEC/SEF, 1997.

D’AMBROSIO, Ubiratan. Educação matemática: da teoria à prática. 22. ed. Campinas, SP: Papirus, 1996.

KOZMINSKI, Edson Luiz. As três partes. São Paulo: Ática, 1998.

NOVAK, Joseph Donald. Uma teoria de educação. São Paulo: Pioneira, 1981. 